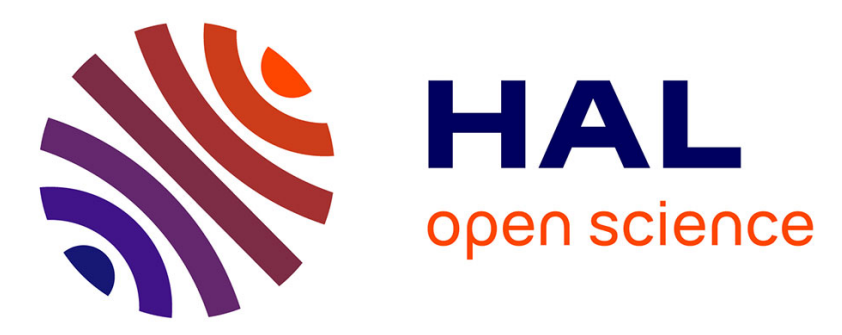

\title{
Stakeholder Mapping in a Collaborative Project for a Sustainable Development
}

\author{
Mohamed Mabrouk, Severine Sperandio, Philippe Girard
}

\section{To cite this version:}

Mohamed Mabrouk, Severine Sperandio, Philippe Girard. Stakeholder Mapping in a Collaborative Project for a Sustainable Development. IFIP International Conference on Advances in Production Management Systems (APMS), Sep 2014, Ajaccio, France. pp.518-525, 10.1007/978-3-662-447369_63. hal-01387927

\section{HAL Id: hal-01387927 \\ https://inria.hal.science/hal-01387927}

Submitted on 26 Oct 2016

HAL is a multi-disciplinary open access archive for the deposit and dissemination of scientific research documents, whether they are published or not. The documents may come from teaching and research institutions in France or abroad, or from public or private research centers.
L'archive ouverte pluridisciplinaire HAL, est destinée au dépôt et à la diffusion de documents scientifiques de niveau recherche, publiés ou non, émanant des établissements d'enseignement et de recherche français ou étrangers, des laboratoires publics ou privés. 


\title{
STAKEHOLDER MAPPING IN A COLLABORATIVE PROJECT FOR A SUSTAINABLE DEVELOPMENT
}

\author{
M. Mabrouk, S. Sperandio, and P. Girard \\ IMS - University of Bordeaux \\ 33401 TALENCE cedex \\ Mohamed.mabrouk@ims-bordeaux.fr; severine.sperandio@ims-bordeaux.fr; \\ philippe.girard@ims-bordeaux.fr
}

\begin{abstract}
Sustainable development is an approach to development which consists in balancing the different environmental, social and economic needs, where many stakeholders are involved. The collaboration about the objectives set by the business members of the project-leading is decisive, but it can prove to be complicated, since each of the stakeholders can adopt various sustainability strategies and practices. This paper proposes an approach for applying stakeholder map for collaborative strategies in order to support the identification of significant partners and thus their involvement within the projects. A certain focus is provided on sustainability issues. The approach is based upon the audit of the different partners of a network in order to know their sustainable expectations and priorities, and their degrees of influence and dependency. It leads to the identification of eight stakeholders families or types, following their involvement, voluntary or not, faced with sustainable development.
\end{abstract}

Keywords: Sustainable Development, Corporate Social Responsibility, Stakeholder map.

\section{$1 \quad$ Introduction}

More than one hundred definitions of sustainable development exist, but the most widely used one is from the World Commission on Environment and Development (1987): it states that sustainable development is a "development that meets the needs of the present without compromising the ability of future generations to meet their own needs" [1]. In the same way, Corporate Social Responsibility (CSR) is the implementation of sustainable development by companies: it represents the company's sense of responsibility towards the community in which it operates. In other words, a company has to increase its profitability and ensure its durability, but has to also consider the needs and interests of all its stakeholders in order to improve their economic, social and environmental performances. This research aims to establish a procedure for developing a stakeholder map for strategic projects in order to facilitate decision making of senior managers in a sustainable context: by taking into account needs and expectations of their partners early in the project, they can more easily ensure satisfaction and performance of these partners and therefore allow the success of the strat-

adfa, p. 1, 2011.

(C) Springer-Verlag Berlin Heidelberg 2011 
egy. With this intention, the paper is organized as follows. In Section 2, general points of stakeholder theory and its impact on a collaborative project are introduced. In Section 3, we develop a methodology to create a stakeholder map in a collaborative project, with sustainable constraints. Finally, some conclusion remarks and discussions are provided in the last section.

\section{What about stakeholder theory}

The collaboration between stakeholders is decisive for the success of any project, particularly in the fields of Sustainable Development (SD) and Corporate Social Responsibility (CSR), where the taking into account of stakeholders' opinions is central in their guidelines. However, all stakeholders belonging to a same system share not necessarily the same concerns and have most of the time different and heterogeneous expectations and priorities. For this, the opportunity to identify and analyze the behavior of these stakeholders can change strategic directions of future development projects. What are the relationships between the different stakeholders? What relative influence do they have? Such an analysis enables the identification of institutions and relationships which need to be developed or dealt with to avoid negative outcomes and enhance positive ones [2]. Of course, the literature overflows with stakeholders' categorizations. The authors note that this theory contributes to understand projects by highlighting the importance of considerations of the stakeholders during planning, due principally to their influence on the project. It can also assist to classify the stakeholders as internal and external [3], primary and secondary [4], according to they are immediately affected by, or can immediately affect the system. The major contribution about relationships between managers and stakeholders and the way to categorize them comes from Mitchell, Agle and Wood [5]. The authors tried to provide a dynamic model allowing to explain how a stakeholder should order its relationships. Their multi-attribute approach is based on three criterions allowing to categorize stakeholders on an organization: the power of the stakeholder to influence the organization, the legitimacy of the relationships in terms of desirability or appropriateness, the urgency (expectations of the stakeholder in terms of criticality and time-sensitivity). Such an analysis is very interesting, since the power or influence analysis between all the stakeholders is paramount in collaborative projects. However, we think that a simple classification is not sufficient when it comes to share and collaborate in the long term. Indeed, the theory does not give a clear guidance on how to exactly understand the settings and implementation, and dialogue aspects and consideration of stakeholders' expectations are not clearly identified. We decide to inspire from this approach to develop a model for applying stakeholder map for collaborative projects in order to support strategies and associated projects to be implemented. A certain focus is provided on sustainability issues. The model is based upon the audit of the different partners of a network in order to know their sustainable expectations and priorities, and their degrees of influence or dependency. 


\section{Aid to stakeholder mapping in a collaborative project, with sustainable issues}

The performance of sustainable strategies depends in a large part to issues related to some actions to be implemented as: establish a constructive dialogue and a transparent communication with its stakeholders; share expertise with its partners; better determine the expectations from the various stakeholders; communicate its commitments and objectives with stakeholders; enhance the structure of the dialogue and adapt it to the needs of different issues. Thus, identify the stakeholders responsible for implementing and contribution of some objectives is a difficult and complex task. We also want to aid decision makings of senior managers by a procedure enabling to identify the "Sphere Of Influence" (SOI), which defines the scope of a company's social responsibility (ISO 26000 ). We base this research on the actors' strategy and on the structural analysis [6], which are two methodologies enabling, by studying relations between the different elements of a same system (organization, network of companies ...), to underline the variables that are essential to the system's evolution. They have the advantage of stimulating reflection within a group, and leading it to think about certain aspects, which are sometimes counterintuitive. Our approach consists in laying down and analyzing the relations between stakeholders: it focuses on issues of sustainable development which represent stakes for the future and around which the actors could build their strategies. However, before beginning any project of development, a company has to know the involvement of its stakeholders and has to recognize stakeholders that can help or impede the completion of the project, depending of the impacts of this project on their own strategies: operational impacts (changes in operating activities), structural impacts (changes of capacities and / or competences of human and technical resources), functional impacts (integration of new technologies, modification of the supply chain, etc.). The associated computer tool is developed under Microsoft Visual Basic for Applications (VBA).

\subsection{Stage 1: Strategic sustainable issues of the company and associated objectives}

This stage, which is the least formal, is crucial: it allows to identify and analyze the strategic vision of the company by the selection of the objectives, for a sustainable development. This multi-objective vision of a sustainable development has been developed by John Elkington (notion of triple bottom line or Triple-P (People, Planet, Profit)) when he has defined sustainability as the balance between economic, social and environmental performances [7]. Here, we consider generic objectives associated to these performances, but also the objectives associated to the performances of bearable aspects (intersection of the environment and the social), viable aspects (intersection of the environment and the economy) and equitable aspects (intersection of the social and the economy) (Table 1). 
Table 1. Strategic objectives for a sustainable development

\begin{tabular}{c|c}
\hline Dimensions & Objectives \\
\hline \multirow{3}{*}{ Social } & Improve wellness and security of the employees \\
\cline { 2 - 2 } & Facilitate the participation \\
\cline { 2 - 2 } Bearable & Create or maintain a social implication \\
\cline { 2 - 2 } & Promote a local development \\
\cline { 2 - 2 } Environme & Respect the best practices with external stakeholders \\
\cline { 2 - 2 } nt & Preserve the natural resources \\
\cline { 2 - 2 } Viable & Communicate on environmental management \\
\cline { 2 - 2 } & Oducate new kinds of consumption and sustainable consumption \\
\hline \multirow{2}{*}{ Economic } & Ensure customer satisfaction \\
\cline { 2 - 2 } & Be more flexible and responsive \\
\cline { 2 - 2 } & Ensure economic and financial performance \\
\hline Equitable & Ensure accessibility and social diversity in the work \\
\cline { 2 - 2 } & Ensure a better socio-economic balance \\
\hline
\end{tabular}

\subsection{Stage 2: Relationships between the different stakeholders}

In this stage, the different stakeholders (or actors) of a company for a project of sustainable development are identified. In this case, for example, we shall consider 6 actors ( $n=6: A_{1}, A_{2} \ldots, A_{6}$ ) corresponding to the customers, suppliers, subcontractors, banks, organisms, co-workers..., interacting with the company. The actor's strategy is also analyzed, as follows:

Matrix of Direct Influences (MDI).The matrix of Direct Influences is a square matrix of order 6 (Actors x Actors). It highlights the direct influences that each actor has on the others (Fig.1). For each cell of the matrix, a score " $x_{i, j}$ " is assigned, depending to the influence that the row variable "i" has on the column variable " $\mathrm{j}$ ". By definition, there is no impact of an Actor on itself (score $=0$ when $i=j$ ). We will use for the different scores the values $0,1,2$ and 3 (no influence, weak influence, medium influence, strong influence), so $x_{i, j} \in[0,3]$.

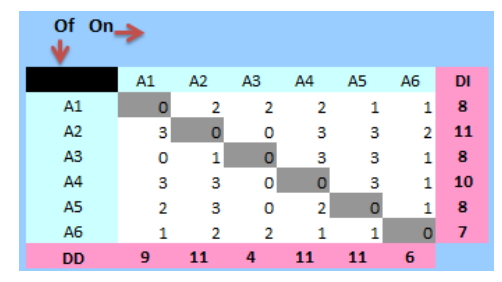

Fig. 1. Matrix of Direct Influences (MDI)

Once the MDI matrix completed, we calculate the degrees of Direct Influences $(D I)$ and Direct Dependencies $(D D)$, for each Actor " $A_{i}$ ", as follows: 


$$
\begin{gathered}
D I_{i}=\sum_{j=1}^{n} x_{i, j} \text { The scores assigned to the row for the } A_{i} \\
D D_{j}=\sum_{i=1}^{n} x_{i, j} \text { The scores assigned to the column for the } A_{j}
\end{gathered}
$$

In this example, the Actor " $A_{2}$ " seems to be in a dominant position because it is the more influent $(D I=11)$, but it is also very dependent of the others $(D D=11)$. However, such a study doesn't enable to conclude on the actors' strategy in the network of partners because an actor can also influence other actors via transitional actors (this is the domino effect). Consequently, we cannot restrict ourselves to the analysis of direct influences, and the following paragraph focuses on the analysis of indirect influences between the different actors.

Matrix of Indirect Influences (MII). The MII matrix allows considering indirect influences of each actor on the others. The $M I I_{i, j}$ matrix, which analyses the impact of the Actor " $i$ " on the Actor " $j$ " via " $n$ " other Actors, is obtained in " $v_{i, j}$ " as follows: $V_{i, j}=\operatorname{Min}\left(M D I_{i, 1} ; M D I_{1, j}\right)+\operatorname{Min}\left(M D I_{i, 2} ; M D I_{2, j}\right)+\ldots+\operatorname{Min}\left(M D I_{i, n} ; M D I_{n, j}\right)=\sum_{k=1}^{n} \operatorname{Min}\left(M D I_{i, k} ; M D I_{k, j}\right)$ where $k \neq i$ and $k \neq j$. Thus, the degrees of Indirect Influences $(\operatorname{InI})$ and Indirect Dependencies (InD), for an Actor “ $i$ ", are:

$$
\begin{gathered}
\operatorname{InI} I_{i}=\sum_{j=1}^{n} v_{i, j} \text { The scores assigned to the row for the } A_{i} \\
\operatorname{InD_{j}}=\sum_{i=1}^{n} v_{i, j} \text { The scores assigned to the column for the } A_{j}
\end{gathered}
$$

Synthesis. At this point, managers have the possibility to weight the different degrees (degrees of Direct and Indirect Dependencies and degrees of Direct and Indirect Influences) according to their knowledge about the market (Fig.2). Then, two synthesis elements are calculated: the Degree of the Overall Influence $(D O I)$ corresponding to

\begin{tabular}{|c|c|c|c|c|c|c|}
\hline Weighting & 1,5 & 1 & 1,5 & 1 & & \\
\hline Actors & $0_{1}^{0.5}$ & DD & InI & $\ln D$ & DOI & DOD \\
\hline A1 & $\frac{15}{25}$ & 9 & 45 & 35 & 26,5 & 22 \\
\hline A2 & $2 \quad 11$ & 11 & 49,5 & 37 & 30,25 & 24 \\
\hline A3 & 8 & 4 & 40,5 & 13 & 24,25 & 8,5 \\
\hline A4 & 10 & 11 & 48 & 35 & 29 & 23 \\
\hline A5 & 8 & 11 & 46,5 & 35 & 27,25 & 23 \\
\hline A6 & 7 & 6 & 40,5 & 25 & 23,75 & 15,5 \\
\hline
\end{tabular}
the weighted average of direct and indirect influences, and the Degree of the Overall Dependence $(D O D)$ corresponding to the weighted average of direct and indirect dependences.

Fig. 2. Synthesis 
These to synthesis elements enable to know the stakeholders to be considered for future collaborations. However, considering that each project has its own characteristics related to one or several strategic objectives (cf. Table 1), they are not sufficient to build precisely the Sphere Of Influence since the positioning of the actors in relation to these objectives is not clarified.

\subsection{Stage 3: Positioning of the actors in relation to the strategic objectives}

Here we research the possible convergences and divergences of the different actors relative to the objectives of the project. Of course, they are different from one objective to another: it is also very important to collect the opinions of the different stakeholders in relation to each objective, in order to understand their positioning towards the project. The Matrix of Actors and Objectives (MAO, Fig. 3) shows this positioning according to a qualitative scale $(-1,0$ and +1 corresponding to the fact that the actor is against, without opinion or favorable to the achievement of the objective).

\begin{tabular}{|ccccccccccccc}
\hline & O1 & O2 & O3 & O4 & O5 & O6 & O7 & O8 & O9 & Supp & Opp & DIN \\
\hline A1 & 1 & 1 & 0 & 1 & 1 & -1 & 1 & 1 & -1 & 6 & -2 & 8 \\
A2 & 0 & -1 & 1 & 1 & -1 & 0 & -1 & -1 & 1 & 3 & -4 & 7 \\
A3 & -1 & -1 & -1 & 0 & -1 & 1 & 1 & 0 & -1 & 2 & -5 & 7 \\
A4 & -1 & -1 & 0 & 0 & 0 & 1 & -1 & 0 & -1 & 1 & -4 & 5 \\
A5 & -1 & 0 & -1 & 0 & 1 & -1 & 1 & 0 & -1 & 2 & -4 & 6 \\
A6 & 1 & 0 & 0 & 0 & -1 & 0 & 1 & 1 & 1 & 4 & -1 & 5 \\
Agreements & 2 & 1 & 1 & 2 & 2 & 2 & 4 & 2 & 2 & & & \\
Disagreements & -3 & -3 & -2 & 0 & -3 & -2 & -2 & -1 & -4 & & & \\
\hline
\end{tabular}

Fig. 3. The MAO matrix

Thanks to the MAO matrix, we can now calculate the Degree of INvolvement $(D I N)$ of the different actors. Therefore, for the Actor " $i$ ":

$D I N_{i}=\operatorname{Supp}_{i}+\left|O p p_{i}\right|$ where Supp is the support level of the Actor "i" (corresponding to the sum of the positive scores assigned to the row of this actor) and $O p p_{i}$ is the opposition level of the Actor "i" (corresponding to the sum of the negative scores assigned to the row of this actor).

Moreover, the matrix enables to know the number of agreements and disagreements for each objective, which can be interesting information to help the decision making of managers.

\subsection{Stage 4: Stakeholder Map}

Here we propose a generic table including eight families of stakeholders, corresponding to the eight possible combinations between the three main attributes (DIN, DOI and $D O D$ : see Table 2). 
Table 2. Stakeholders Classifications

\begin{tabular}{|c|c|c|c|c|c|c|c|c|}
\hline Attribute SH Mapping & $(1)$ & $(2)$ & $(3)$ & $(4)$ & $(5)$ & (6) & (7) & (8) \\
\hline DIN & - & - & - & - & + & + & + & + \\
\hline DOI & - & - & + & + & - & - & + & + \\
\hline DOD & - & + & - & + & - & + & - & + \\
\hline
\end{tabular}

(1) The Dormant Stakeholders: they have no power (or a weak power) and are neither dependent nor involved (low level of the three attributes). They don't need a special attention and need only a minimum monitoring.

(2) The Dependent Stakeholders: They have a high level of dependency but low levels of influence and involvement (follower stakeholders). The existence of a contract with them leads to the necessity for the managers to follow their activities.

(3) The Influential Stakeholders: their interest for the project is low but they are powerful. No emergency action is requested because they aren't a part of the project, but managers must satisfy their possible requirements.

(4): The Influential and Dependent Stakeholders: they are both powerful and dependent. They have their own ways to carry out their projects, but are also influenced by the actions of the other stakeholders. Such a category of actors has to be seriously monitored.

(5) The Interested Stakeholders: They have a high level of involvement but are neither influential nor dependent. They can't engage a pressure on the company but it's necessary to keep them informed since they can be considered as potential collaborators (for example: associations, consulting firm).

(6) The Involved and Dependent Stakeholders: they are involved but dependent. They aren't powerful (subcontractor for example): they also can't engage pressures on the company, but it's necessary to inform them for any progression in the project.

(7) The Dominant and Involved Stakeholders: they are both powerful and interested in the project. Their cooperation is essential to ensure the feasibility of the project.

(8) The Primordial Stakeholders: they are powerful, interested in the project, and dependent. Managers are obliged to establish a privileged relationship for responding to their needs and expectations.

We will consider that the Sphere of Influence to be considered for a project includes all the actors interested in the project and can help its completion: these are the categories (6), (7) and (8).

\section{Conclusion}

Stakeholder theory has its roots from management literature and was developed as a response to the needs to successfully carry out strategic processes in the context of 
profit-organizations. Here, the approach of stakeholder analysis has been completed and oriented towards sustainable development issues. The existence of an approach that allows collecting different opinions and strengthening the dialogue between the different stakeholders is critical to a long-term success. Resource managers can thus intervene in the interest of development and improvement of future projects, in order to re-evaluate the strategic objectives initially set, revise the different contracts with stakeholders, regularly maintain and update the different classes of stakeholders. In this paper, we have tried to overcome many limits related to stakeholder theory and have created a model for decision making in a collaborative and sustainable context: this model enables to identify the stakeholders with whom it is recommended to collaborate. The purpose is also to build the strategies to be implemented, taking into account the expectations of the different stakeholders, in order to ensure the satisfaction of these partners and therefore allow the success of future collaborations. Our work has demonstrated its ability to not only contribute to select suitable stakeholders, but also provide a guide to strategic management for sustainable development issues. However, we cannot neglect some weaknesses of this theory which can be ambiguous and subjective. Indeed, the categorization process depends on the evaluators and their analysis can be influenced by their backgrounds, environment or people involved in the process. It is also subject to indirect aspects such as honesty and reliability of the collected information.

\section{References}

1. Brundtland Commission. Report of the World Commission on Environment and Development. United Nations (1987).

2. Mayer, J. Stakeholder power analysis. Power Tools Series. London, United Kingdom: International Institute for Environment and Development. (2005).

3. Clarkson, M.B.E. A Stakeholder framework for Analysing and Evaluating Corporate Social Performance, Academy of Management Review, vol. 20(1), p. 92-117 (1995).

4. Caroll A. B. Business and Society: Ethics and Stakeholder Management, O.H.: South Western, Cincinatti (1989).

5. Mitchell R. K., Agle B. R., Wood D. J. Toward a Theory of Stakeholders Identification and Salience: Defining the Principles of who and what really Counts, Academy of Management Review, vol. 22, n², pp. 833-886 (1997).

6. Arcade, J., Godet, M., Meunier, F. and Roubelat, F. Structural analysis with the MICMAC method \& Actors strategy with MACTOR method, Futures Research Methodology, American Council for the United Nations University: The Millennium Project (1999).

7. Elkington, J. Cannibals with Forks: The triple bottom line of 21 st century business. Capstone: Oxford (1997). 